\title{
REDUCTION OF SILVER IONS USING CHITOSAN AND INVESTIGATION OF THEIR REACTIVITY
}

\author{
Irina G. Antropova*, Natalia V. Panferova, Eldar P. Magomedbekob
}

Mendeleev University of Chemical Technology of Russia, Moscow

\begin{abstract}
In this work, the reactivity of low-molecular-weight chitosan with a hydroxyl radical was evaluated. An enhancement of the antioxidant properties of chitosan in the presence of silver ions has been shown. It has been determined that under the action of irradiation on the chitosan-silver system, silver nanoparticles are formed, the size of which can be controlled by the type of action on the system.
\end{abstract}

Key words: Chitosan, nanoparticle, radiation, spectophotometry, reactivity

\section{INTRODUCTION}

Scientists are studying nanoparticles (NPs), as they can be carriers of biologically active substances. The body reacts positively to silver particles without causing allergic reactions and rejection. During penetration to the target, the system should not lose its biological activity, which can be successfully accomplished thanks to chitosan with silver nanoparticles $[1,2]$. Chitosan (CS) is a chitin derivative and it is the second most common polysaccharide after cellulose. Its qualities are non-toxicity, biodegradability, antibacterial activity, ability to form complexes, etc.

At the onset of a certain stage (when NPs transform into a larger size), the stabilizer (chitosan) begins to act: its molecules capture the particle, which prevents it from sticking to the rest [3]. When studying the effect of synthesis conditions on the size of NPs, it is necessary to take into account the concentration of silver ions in solution, concentration of polymer molecules, molar ratio [monomer]: $[\mathrm{Ag}+]$, molecular weight of polymers and their chain length, temperature, type of solvent and its $\mathrm{pH}$. The aim of the scientific work was to show the effect of irradiation on the reduction of silver ions by using chitosan. The tasks were to study the reactivity of chitosan $11 \mathrm{kDa}$ and $48 \mathrm{kDa}$ by the method of competing reactions and to study the reduction of silver ions by low-molecularweight chitosan under the action of photo- and X-ray radiation.

\section{MATERIALS AND METHODS}

CS had a molecular weight of $11 \mathrm{kDa}(\mathrm{CS}-11)$ and $48 \mathrm{kDa}(\mathrm{CS}-48)$ with a degree of deacetylation of $3 \%$ (Bioprogress, Russia). The process of obtaining nanosilver particles was carried out by photo- and $\mathrm{X}$-ray exposure to the systems in the presence of oxygen. Photo-irradiation was carried out on an OSL-1 lamp manufactured by Omo, Russia; the activity was $2.4 \times 1018$ quantum / s according to a ferrioxalate actinometer. The solutions were irradiated at Mendeleev University of Chemical Technology of Russia using an X-ray installation (X-ray tube 5BHV6 - W with incomplete protection from unused Xray radiation, with one working radiation beam). The dose rate according to the Fricke dosimeter is equal to $3.00 \pm 0.01 \mathrm{~Gy} / \mathrm{s}$ [4-6].

The measurements were carried out on an SF-2000 spectrophotometer, Fluorat-02-panorama $(\lambda$, ex $=312 \mathrm{~nm}, \lambda$, reg $=430 \mathrm{~nm})$, Russia, Hitachi HT770 microscope, USA.

\section{RESULTS AND DISCUSSIONS}

The relative rate constant of the reaction with $\mathrm{OH}$ radicals was determined by the method of competing reactions using terephthalic acid (equation 1,2). The process of interaction of terephthalic acid with $\mathrm{OH}$ radicals is presented (Equation 1).

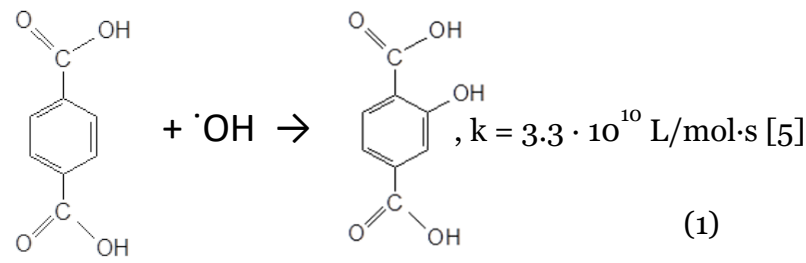

$\mathrm{CS}+{ }^{\circ} \mathrm{OH} \rightarrow \mathrm{CS}-\mathrm{OH}$, unknown $\mathrm{k}$

The influence of the molecular weight of chitosan on its reactivity with the OH-radical is shown (Figure 1); the higher the molecular weight, the higher the reactivity.

\footnotetext{
*antropovai@muctr.ru
} 


\section{W(Acceptor)/W(CS)}

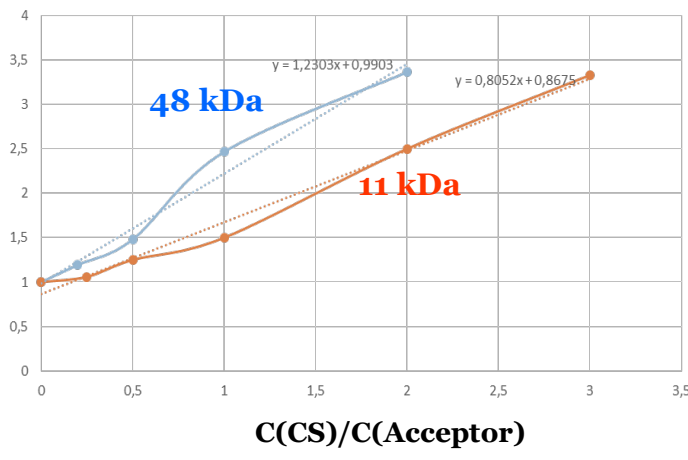

Figure 1. Dependence W(Acceptor)/W(CS) of $\mathrm{C}(\mathrm{CS}) / \mathrm{C}($ Acceptor)

It is established that the molecular weight of a chemical compound affects on their reactivity in a reaction with a hydroxyl radical. In reaction with a $\mathrm{OH}$-radical, the reactivity of $\mathrm{CS}(11 \mathrm{kDa}) / \mathrm{H} 2 \mathrm{O}<\mathrm{CS}(48$ $\mathrm{kDa}) / \mathrm{H} 2 \mathrm{O}$ and for the system $\mathrm{CS}(11 \mathrm{kDa}) / \mathrm{Ag}+>\mathrm{CS}$ $(48 \mathrm{kDa}) / \mathrm{Ag}+$.

The relative reaction rate constant $\mathrm{CS}$ is established, which is equal to $2.6 \times 10^{10} \mathrm{~L} / \mathrm{mol} \cdot \mathrm{s}$ for CS with $\mathrm{Mw}=11 \mathrm{kDa}$, and $4.0 \times 10^{10} \mathrm{~L} / \mathrm{mol} \cdot \mathrm{s}$ for $\mathrm{CS}$ with $\mathrm{Mw}=48 \mathrm{kDa}$. The molecular weight of the polymer CS affects its reactivity in the reaction with the hydroxyl radical. It is antioxidant properties of CS.

When studying the system of CS with silver ions, it is shown that the relative rate constant of the reactions of CS (11 kDa) / Ag+ is equal to $1.8 \cdot 10^{11} \mathrm{~L} / \mathrm{mol} \cdot \mathrm{s}$ and for the system of CS $(48 \mathrm{kDa}) / \mathrm{Ag}+$ is equal to $8.8 \cdot 10^{10}$ $\mathrm{L} / \mathrm{mol} \cdot \mathrm{s}$. The antioxidant properties of CS are higher in the presence of silver nitrate.

The CS polymer contains $\mathrm{OH}-$ and primary amino groups that carry a positive charge in aqueous media at acidic and neutral $\mathrm{pH}$ values, which determines the possibility of the formation of a polysaccharide in a nanostructured state.

It was found that after two hours of exposure to radiation with a power of $3 \mathrm{~Gy} / \mathrm{s}$, a new surface of plasmon resonance (SPR) is observed in the region of 360-500 nm, the color of the solution changes to a light yellow color (Figure 2). The solution remained stable, no precipitate was observed in the solution over time.

In the case of photolysis (Figure 4), After exposure for $20 \mathrm{~min}(3.1 \times 1021$ quanta), the presence of two maxima at $410 \mathrm{~nm}$ and $515 \mathrm{~nm}$ was noted, which indicates that NP-Ag of several sizes formed in the solution.

The matrices of NPs-Ag with CS were directly examined under a Hitachi HT 7700 microscope (Fig.3). Using this microscope, it was possible to establish that the smallest NP-Ag size is obtained with chitosan- 48 $\mathrm{kDa}$, and the largest when using CS $-11 \mathrm{kDa}$.

In the case of photolysis (Figure 4) after exposure for $20 \mathrm{~min}\left(3.1 \times 10^{21}\right.$ quantum $)$, the presence of two maxima at $410 \mathrm{~nm}$ and $515 \mathrm{~nm}$ was noted, which indicates that NP-Ag of several sizes formed in the solution.

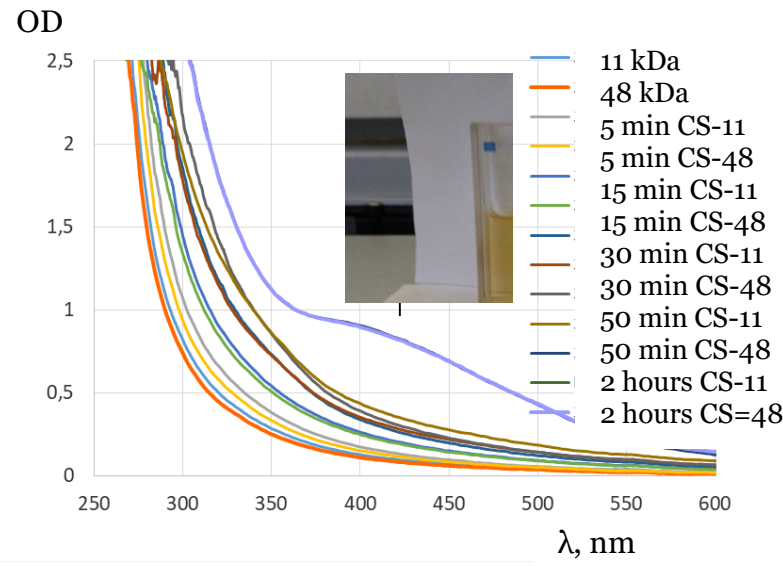

Figure 2. Evolution of the optical absorption spectra of CS (11 kDa and $48 \mathrm{kDa}$ ) / Ag + depending on the time of X-ray exposure in the presence of atmospheric oxygen

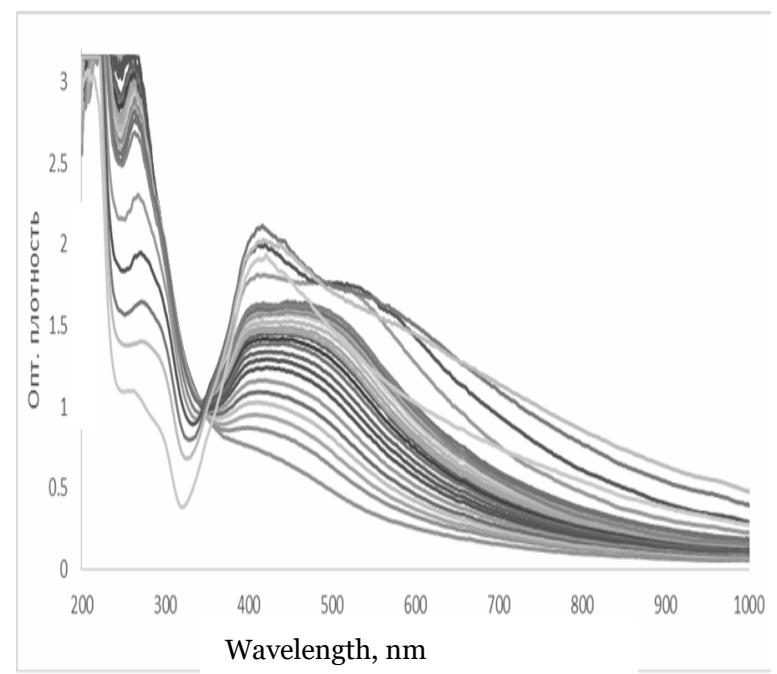

Figure 3. Photolysis. Evolution of the optical absorption spectra of CS/water/Ag+ as a function of the photo-action time (min).

Below is a table comparing all irradiated systems (Table 1). It is established that the larger the exposure dose, the more particles are in the solution (the particle size decreases in this case).

Table 2. Dimensions of NP-Ag / CS depending on the type of exposure to the system (X-rays, photo exposure).

\begin{tabular}{|c|c|c|}
\hline Radiation & Particle size, $\mathrm{nm}$ & SPR, $\mathrm{nm}$ \\
\hline Radiolysis & & \\
$2.4 \mathrm{kGy}$ & $\begin{array}{c}30-60(\mathrm{CS}-11) \\
20-40(\mathrm{CS}-48)\end{array}$ & $360-500$ \\
& $\begin{array}{c}50-80(\mathrm{CS}-11) \\
40-50(\mathrm{CS}-48)\end{array}$ \\
\hline $7.2 \mathrm{kGy}$ & $30-60(\mathrm{CS}-11)$ & $350-600$ \\
& & $\lambda \max \sim 420,477$ \\
\hline $\begin{array}{c}\text { Photolysis } \\
\text { min }\left(3.1 \cdot 10^{21}\right. \\
\text { quantum) }\end{array}$ & & \\
\hline
\end{tabular}

It is shown that under X-ray at a dose of $2.4 \mathrm{kGr}$ on the $\mathrm{CS} / \mathrm{Ag}+$ system, the silver nanoparticle size is 30-60 $\mathrm{nm}$ when using CS with Mw $11 \mathrm{kDa}$, the size is 20-40 nm when using CS with Mw $48 \mathrm{kDa}$ (plasmon 
I. G. Antropova et al., Reduction of silver ions using chitosan..., RAD Conf. Proc., vol. 5, 2021, 115-118

resonance band in the region of $360-500 \mathrm{~nm}$ ), and at photoactivity the size of silver nanoparticle is 30-60 $\mathrm{nm}$ (plasmon resonance band in the region of $350-600 \mathrm{~nm})$. It can be concluded that under the action of X-ray radiation on solutions of $\mathrm{CS} / \mathrm{Ag}+$ the

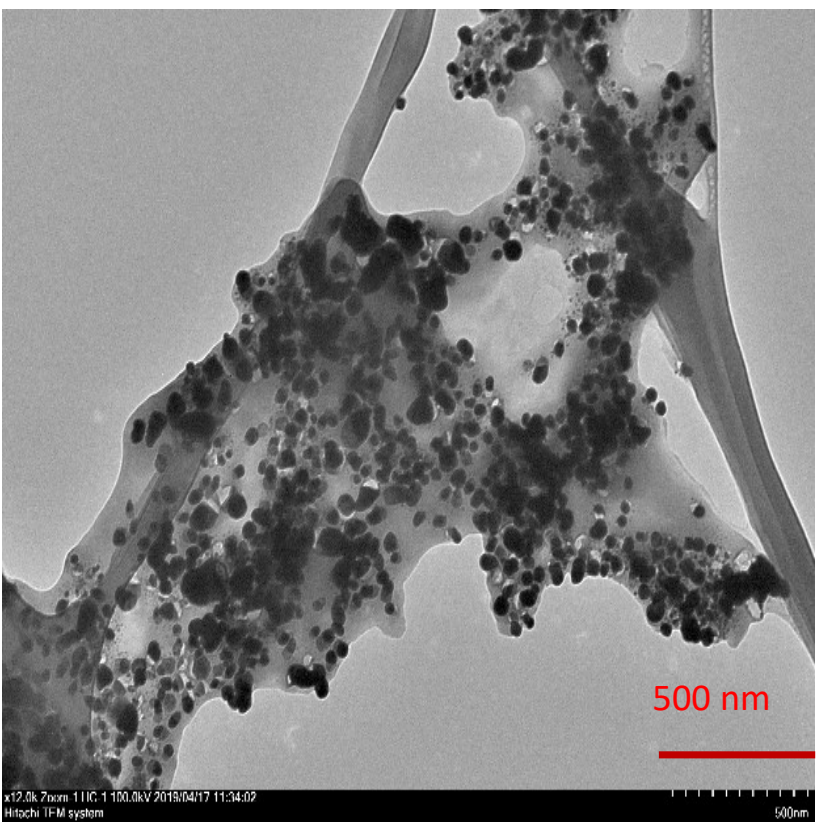

particle size is lower, the higher the molecular weight of CS, the lower the size of silver nanoparticles, and it is also noted that under X-ray exposure, the particle size is smaller than under photo-radiation.

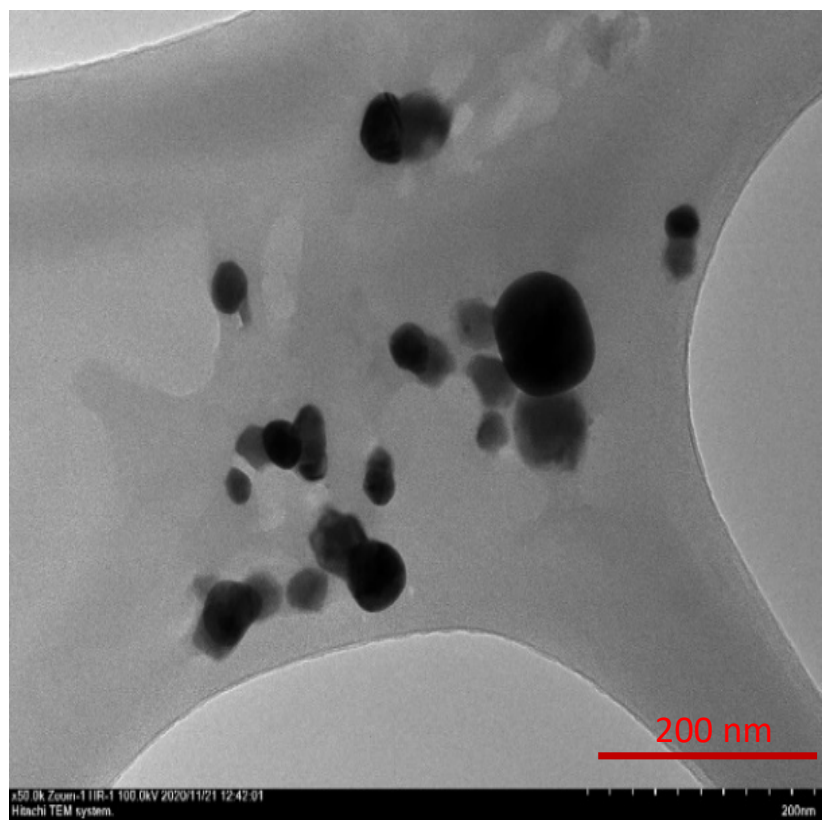

Figure 4. TEM-image of silver nanoparticles synthesized in the CS-11 ( $k D a) A g+$ system under the action of X-ray radiation. $D=7.2 \mathrm{kGy}$
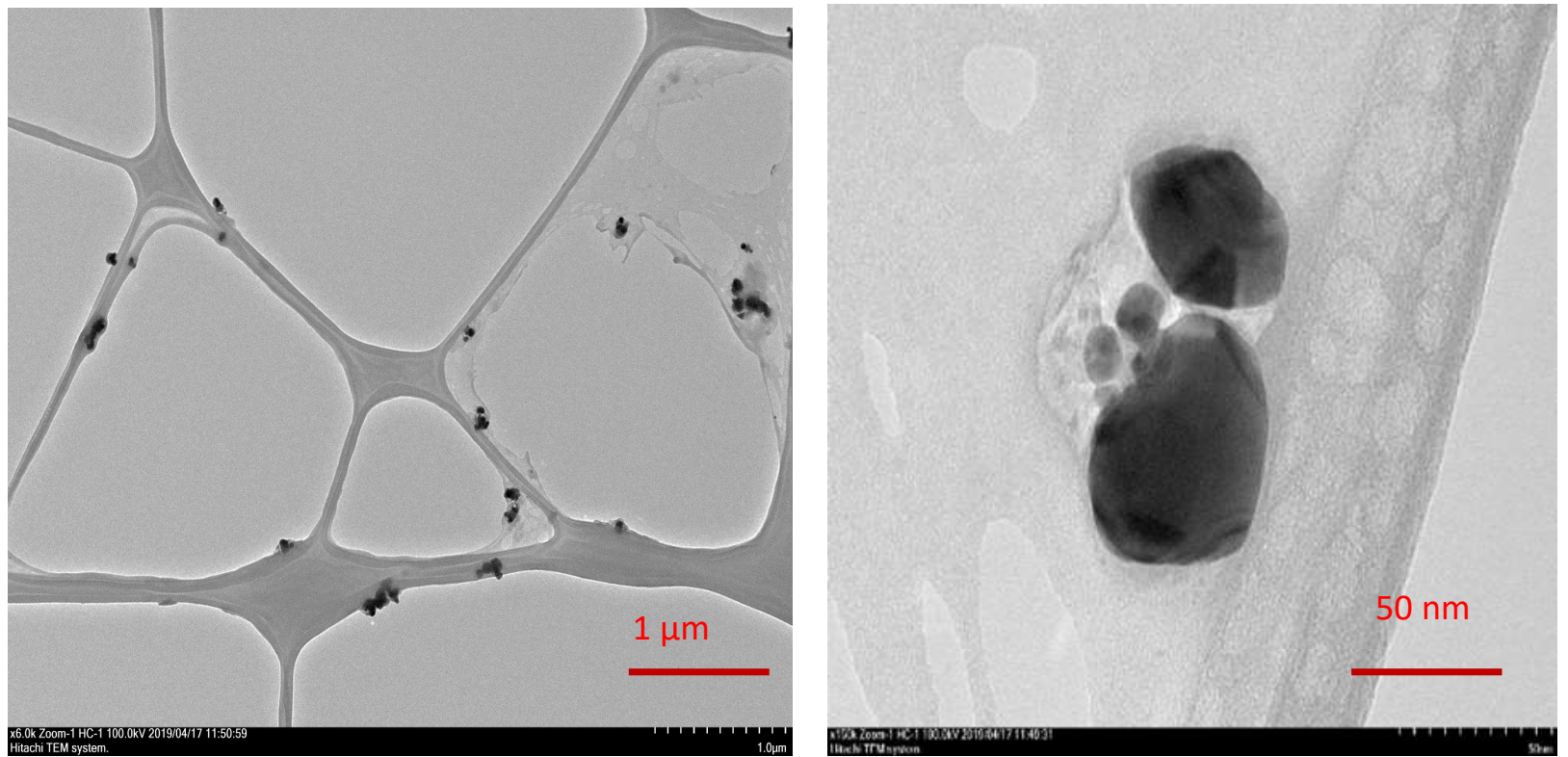

Figure 5. TEM-image of silver nanoparticles synthesized in the CS $11(\mathrm{kDa}) \mathrm{Ag}+$ system under the action of photo-radiation 


\section{CONCLUSION}

The work revealed the antioxidant properties of an aqueous chitosan solution due to the interception of the hydroxyl radical. In this work, the relative rate constant of the interaction of $\mathrm{CS}$ with $\mathrm{OH}$ radicals was determined by the method of competing reactions using terephthalic acid. It has been shown that the molecular weight of CS affects its reactivity in the reaction with a hydroxyl radical; the higher the molecular weight, the higher it is. When studying the CS system with silver ions in water, it was shown that the relative rate constant of the $\mathrm{CS}-11 / \mathrm{Ag}^{+}$reactions with the $\mathrm{OH}$ radical is 2 times higher than the rate constant of the CS-48 / $\mathrm{Ag}^{+}$. The use of high-energy chemistry in the reduction of silver ions with an aqueous solution of low-molecular-weight chitosan is a promising method in which the reaction product is obtained without impurities as a by-product. Particle size can be controlled by exposure dose and type of radiation.

Acknowledgements: The work was supported by Mendeleev University of Chemical Technology of Russia. Project Number 2020-16.

\section{REFERENCES}

1. S-H. Lim, S. M. Hudson, "Review of chitosan and its derivatives as antimicrobial agents and their uses as textile chemicals," J. Macromol. Sci. Pt. C, vol. 43, no 2, pp. 223-269, 2003. https://doi.org/10.1081/MC-120020161

2. M. G. Grigoriev, L. N. Babich, "The use of silver nanoparticles against socially significant diseases," Young Scientist, vol. 9, pp. 396-401, 2015.

3. K. Zielinska, A. G. Shostenko, S. Truszkowski, "Analysis of chitosan by gel permeation chromatography," High Energy Chemistry, vol. 48, pp. 72-75, 2014 http://doi.org/10.1134/So018143914020143

4. A. A. Fenin, I. G. Antropova, S. V. Gornostaeva, Laboratory Workshop on Radiation Chemistry, D. Mendeleev University of Chemical Technology of Russia, Moscow, Russia, 2016.

5. М. Я. Мельников, Экспериментальные методы химии высоких энергий, Москва, Россия: МСУ, 2009.

(M. Y. Melnikov, Experimental Methods of High Energy Chemistry, Moscow, Russia: MSU, 2009.)

6. А.К. Пикаев, Современная радиационная химия: Радиолиз газов и жидкостей, Москва, Россия: Наука, 1986.

(A. K. Pikaev, Modern radiation chemistry: Radiolysis of gases and liquids. Moscow, Russia: Science, 1986.) 